\title{
Mining
}

http://dx.doi.org/10.1590/0370-44672021740022

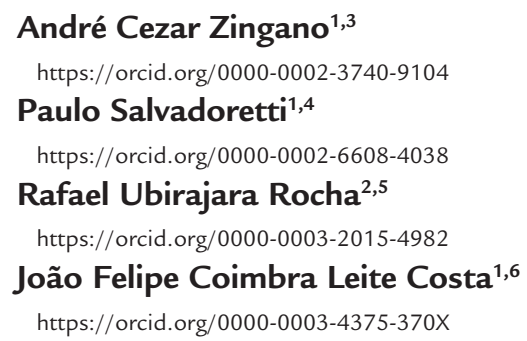

${ }^{1}$ Universidade Federal do Rio Grande do Sul - UFRGS Departamento de Engenharia de Minas,

Porto Alegre - Rio Grande do Sul - Brasil.

${ }^{2}$ Universidade Federal do Rio Grande do Sul - UFRGS Laboratório de Pesquisa Mineral e Planejamento Mineiro, Porto Alegre - Rio Grande do Sul - Brasil.

E-mails: ${ }^{3}$ andrezin@ufrgs.br, andre.zingano@gmail.com 4paulo.salvadoretti@ufrgs.br, ${ }^{5}$ rafaelubir@gmail.com 6jfelipe@ufrgs.br

\section{Estimating uniaxial compressive strength, density and porosity of rocks from the $p$-wave velocity measurements in-situ and in the laboratory}

\begin{abstract}
Knowledge of the physical properties of rock masses is fundamental for the economics and safety of mining projects. The determination of these properties in rock samples in the laboratory requires time, expensive equipment and qualified personnel, which considerably increases the information's cost. Indirect methods were developed to obtain properties related to rock masses, which have been shown to be a viable alternative to traditional procedures. The determination of the compressional mechanical wave velocity $(\mathrm{V} p)$ and subsequent correlation with lithological mechanical properties are indirectly obtained. This study's objective was to obtain correlations between $\mathrm{Vp}$ and the resistance to uniaxial compression, UCS (Unconfined Compressive Strength), as well as the density and porosity of the siltstone and sandstone lithologies present in the coalfield of Candiota, located in the southern region of Rio Grande do Sul, Brazil. The $V p$ records were obtained in laboratory samples, using ultrasonic velocity sensors, and in-situ by geophysical well logging (directly in boreholes). The results indicate the possibility of using $V p$ to determine the physical parameters of the investigated lithologies. In the specific case of the correlations between $V_{p}$ and Unconfined Compressive Strength, determination coefficients R2 above 0.70 were obtained, indicating sufficiently high reliability for using this information (e.g. in roof support projects). The correlation between $\vee p$ and density was also high.
\end{abstract}

keywords: sonic logs; p-wave velocity; uniaxial compression strength.

\section{Introduction}

The mechanical and physical properties of rocks are vitally important in the planning of open-pit or underground excavations and analysis of the stability of slopes, caves and other geological structures. The determination of these properties through the testing of rock samples is a time-consuming and costly activity, which requires accuracy in obtaining, prepar- ing, and testing the samples. Thus, there is a need for simple and reliable, indirect techniques to determine the mechanical and physical properties of rocks.

Determination of P-wave velocity $(V p)$ is an easily applied, non-destructive technique that has increased in its use in geotechnical engineering and can be used to determine geomechanical parameters, either in-situ or in the laboratory. The $\mathrm{P}$-wave velocity is strongly related to intact rock properties, in addition to its structure and texture. Among the parameters that influence $P$ wave velocity are elastic modulus, density, porosity, shape, anisotropy, presence of water, confining pressure, temperature, and discontinuities.

Several studies present the principles 
and applications of determining the $\mathrm{P}$-wave velocity in the laboratory using ultrasonic transducers (source and sensors) for measuring $V_{p}$ in rock samples, generally derived from sounding cores. Kahraman (2001) evaluated the correlations between uniaxial compressive strength (UCS) and other rock strength indicators with the $\mathrm{P}$-wave velocity. Kahraman (2002) estimated the P-wave velocity in intact rock from indirect measurements in the laboratory. Khandelwal and Singh (2009) correlated Vp with different physical-mechanical properties (e.g. UCS, porosity, density) of the rocks present in coal deposits (coals, shales and sandstones). Khandelwal and Ranjith (2010) obtained correlations of Vp with properties of different lithological types. Kurtulus et al. (2012) studied the physical and mechanical properties of ultra-basic serpentinite rocks in Turkey. Fener (2011) studied the effect of the sample size of compact rocks of different types (sedimentary and igneous) and their influence on the measured values of $\mathrm{Vp}$.

When it comes to determining the P-wave velocity directly in boreholes (i.e. in-situ), the sonic well logging technique (sonic $\log$ ) is the resource to be used. Geophysical well logging is an indirect

\section{Location of the study area}

The present study was carried out at the Seival coalfield, located in Candiota,

Rio Grande do Sul State (Figure 1), in an area operated by Copelmi Mineração Ltda.

\subsection{Geological setting}

The Candiota deposit (in the geological context of the Seival Mine) is situated along the outcrop belt of the Paraná basin, located in the South American continent's central-eastern portion and distributed between Brazil, Uruguay, Paraguay, and Argentina. The method for obtaining petrophysical information in boreholes. Sensors inserted in the boreholes allow continuous determination of the physical properties of lithologies intercepted by them. Among the various types of well logging sensors available, the sonic log allows the recording of the P-wave velocity in the lithologies adjacent to the drill holes. A detailed description of this type of sensor, including its possible uses, can be seen in Hearst et al. (2000) and Ellis and Singer (2007). Specifically related to the use of sonic logs in carboniferous basins, they have routinely been used to estimate UCS in Australia's coal mines for roof support projects (McNally, 1987). Such estimates are obtained by measuring $V_{p}$ in boreholes, which are correlated with UCS measured in rock samples from the same holes. The original study by McNally (1987) used sonic log data from 16 mines in Australia's coal deposits. Currently, most Australian mines have specific correlations (Zhou, 2001). The Vp can also be obtained in diamond drilling holes or in destructive drilling. In current practice, the extraction of cores has been reduced after the development of correlations. Examples of similar studies in North America are seen in Wade (1997),
Paraná Basin is an intra-cratonic basin that developed under the continental crust (filled with sedimentary and volcanic rocks), dating from the Ordovician to the Cretaceous period.

The coal found in the region is attributed to the Rio Bonito Formation, which is
Oyler et al. (2010), Karacan (2009a, b). In the latter, the use of full-wave probes is demonstrated, allowing the estimation of dynamic modulus (Young, Shear, Poisson, and Bulk) of the considered lithologies, depending on the determination of the $\mathrm{S}$-wave velocity.

Within this context, the present study uses the determination of $V_{p}$ in laboratory samples and by in-situ sonic logging in the rocks present in carboniferous basins (in this case, siltstones and sandstones), correlating these measurements with mechanical and physical properties of the lithologies (uniaxial compressive strength, density, and porosity). This study investigates how UCS versus $V_{p}$ regressions obtained by sonic logging (similar to those reported by McNally, 1987) can be established in carboniferous basins in Brazil, with a coefficient greater than or equal to 0.70 , which is considered acceptable from the point of view of international practice.

The Vp was correlated with UCS for sandstone and conglomerate rocks from copper and lead ore deposits (Freitas et al., 2017). The species were prepared and the $V p$ and $V s$ were measured. The same species went to the frame machine for UCS tests. composed of river and marine sandstones, carbonaceous siltstones, and shales dating from the Lower Permian period. In the Seival deposit, there are 17 coal layers, with a more significant economic interest in the Candiota Superior, Banco Louco, and Candiota Inferior layers (Schneider et al., 1974).

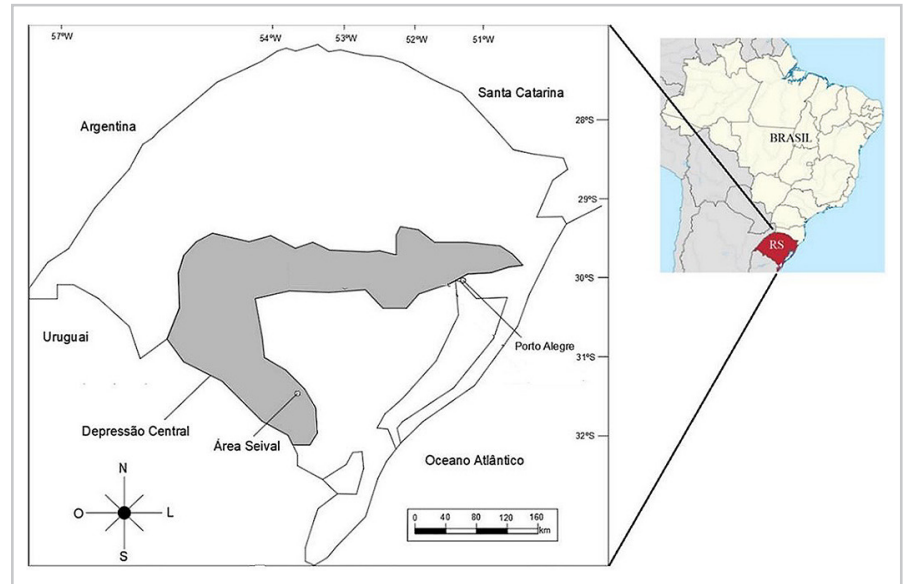

Figure 1 - Location map of the Seival Area, Candiota-RS. 


\section{Materials and methods}

In this study, 46 samples of sandstones and siltstones were prepared. The rock specimens were obtained by diamond drilling (diameter NX), which generated samples of approximately
$53.50 \mathrm{~mm}$ in diameter.

For determining the P-wave's ultrasonic velocity in laboratory samples (Figure 2), the Pundit PL 200 equipment (PROCEQ) was used. The acquisition of sonic $\log$ data (Figure 3) was obtained with a SlimHole Fullwaveform Triple Sonic profiler (Robertson Geologging Ltd., UK). In the uniaxial compressive tests, a Control Advanced 9 hydraulic press was used.

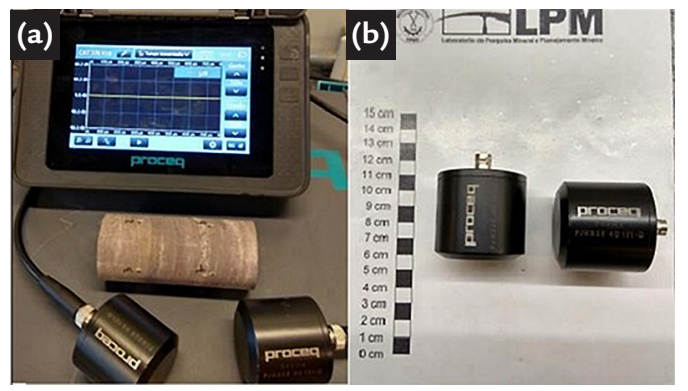

Figure 2 - (a) Pundit and transducers used in the Vp determination tests.

(b) Detail of the $54 \mathrm{kHz}$ frequency transducers used in data acquisition.

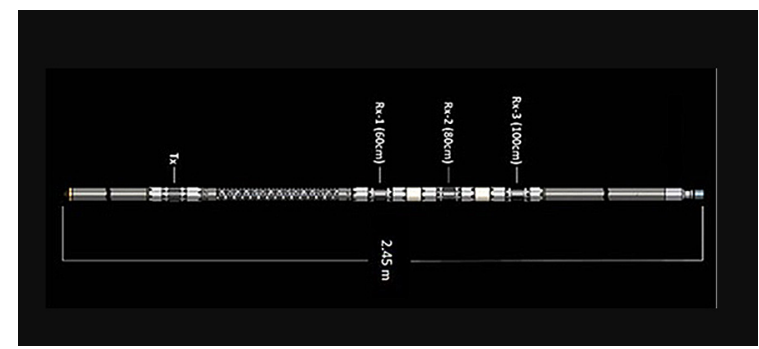

Figure 3 - Schematic diagram of the Slim-Hole Full Waveform Triple Sonic tool, showing the piezoelectric transducer positions (23 kHz) TX and RX1, RX2, RX3 (source and receivers, respectively). (Robertson Geologging Ltd., 2007).

\subsection{Sample preparation}

The drill cores were sawn to generate samples of the length required by the technical standard (ASTM, 2001). This

\subsection{Determination of $V p$ by sonic logging ( $\left.V p \_s o n i c\right)$}

The theoretical and practical aspects of using the sonic log are presented in Hearst et al. (2007) and Ellis and Singer (2007). The specific type of sonic profiling device used in this study is suitable for the mining industry, where boreholes are typically small in diameter $(100 \mathrm{~mm}$ or smaller). It is a device with a transmitter and three receivers, which performs "non-compensated" readings of full waveforms recorded in each sensor, from a pulse of a few microseconds of duration and a frequency of $23 \mathrm{kHz}$, emitted by a piezoelectric transmitter. The mechanical waves from the transmitter propagate travel through the fluid and rocks adjacent to the device. They are registered in the sensors. The difference between wave ar- standard establishes an optimal relationship between the height and diameter of the specimen, 2.5 for cylindrical bodies.
It also establishes that the surfaces of the ends must not deviate perpendicularly by more than $0.25^{\circ}$. rival times (transit) between two of these sensors is used to determine the velocity of the first compressional P-wave (Vp). Most sedimentary rocks have $V p$ velocities ranging from 2,000 to $7,000 \mathrm{~m} / \mathrm{s}$.

The sonic tool used here measured every centimetre along the borehole. However, it is essential to highlight the minimum vertical limit of detection, which in the specific case is $0.20 \mathrm{~m}$, due to the distance between sensors in the equipment. In the present study, to obtain $V_{p}$, we used the difference in transit times of the acoustic wave verified in the RX2 and $\mathrm{RX} 1$ receivers. Thus, in sonic logging, the compressional wave transit time between two receivers represents an average of the rocks' behavior in the $0.20 \mathrm{~m}$ range.
Conversely, the samples used for UCS tests and ultrasonic tests are shorter (up to $135 \mathrm{~mm}$ ). Even when the depths of the rock samples and the profiling records are perfectly correlated, the different sample supports produce dispersion in the correlations between UCS (or ultrasonic velocity) and $V p$ velocities obtained by the sonic log.

To obtain more representative measurements in this study, reducing the effects of the difference between vertical resolution of the sonic log and sample length (Oyler, 2010), we tried to analyse samples of homogeneous lithologies. In this case, the profiling readings were approximately constant and with thicknesses significantly more significant than the distance between the sonic tool's receivers.

\subsection{Determination of $V p$ in laboratory samples ( $V p \_$Pundit)}

For this test, the Pundit equipment was used, whose transducers (transmitter and receiver) are made of piezoelectric ceramic elements. The transducers operate

at $54 \mathrm{kHz}$ and are capable of essentially generating compressional waves for measuring the compressional wave transit time. The test was based on the interna- tional standard (ASTM, 2008) and the transducers were positioned at the ends of the specimens. The transformation equation of the transit time to wave velocity $V p$ is: 


$$
V p(\text { média })=\frac{\Delta d}{\Delta t}
$$

where $\Delta d$ is the specimen's size, $\Delta t$ is the transit time of the pulse in the specimen, and $v_{p}$ is the P-wave velocity.

\subsection{Determination of UCS}

The uniaxial compression test (UCS) was performed using the standard ASTM (1995), which defines this test. Another standard (ASTM, 2001) was used in sample preparation. A total of 42 specimens were prepared (by measuring and weighing) and then tested by the uniaxial compressive test,

\subsection{Determination of physical properties}

The apparent densities and porosities of the samples were determined according to the Brazilian technical

standard ABNT (2010). It was not possible to apply this methodology to all samples, since this method presents a performed on the Advanced 9 press. The test was carried out with a loading rate of $500 \mathrm{kN} / \mathrm{s}$.

stage in which the samples are immersed in water and some of them had degraded due to contact with fluid.

\section{Results and discussion}

The correlations obtained in this study involved wave velocities $V p$ (deter- mined by sonic profiling and Pundit) and physical-mechanical properties (UCS

\subsection{Correlation between Vp_Sonic and Vp_Pundit}

Comparisons were made between the speeds of the sonic waves obtained through different tests. Since the dimensions of the samples used in the tests are different (the volume of rock involved in the measurement of $\mathrm{V}_{\mathrm{p}}$ sonic is more significant than in Vp_pundit), different values for $V p$ were also expected. A comparison was made of the average velocity for $\mathrm{V} p$ Sonic for each sample (in the range of $200 \mathrm{~mm}$ vertical resolution of the sonic profiling) with the $V p$ determined by Pundit (maximum sample length equal to 135 $\mathrm{mm})$. Figure 4 shows this comparison; there was a tendency for ultrasonic velocity (Vp_Pundit) to show the highest values. It is not the objective of this work to study these differences more deeply. However, among the factors that can explain these differences, it should be noted that: (a) as the volume of rock is different in each $V p$ measurement technique, the $V p \_s o n i c ~ v e-$ resistances, porosity, density) of sandstones and siltstones in the area of interest.

locity can be more affected by the presence of small fractures in the in-situ rock; (b) the frequency of the compressional wave generated in each measurement technique is different and the literature informs us that pulses with different frequencies also present a $\mathrm{Vp}$ that is different in solids (see Philippidis; 2005, for example); (c) the diameter of the specimens has an influence on the compressional velocity Vp_Pundit (as shown in Fener; 2011, for example).

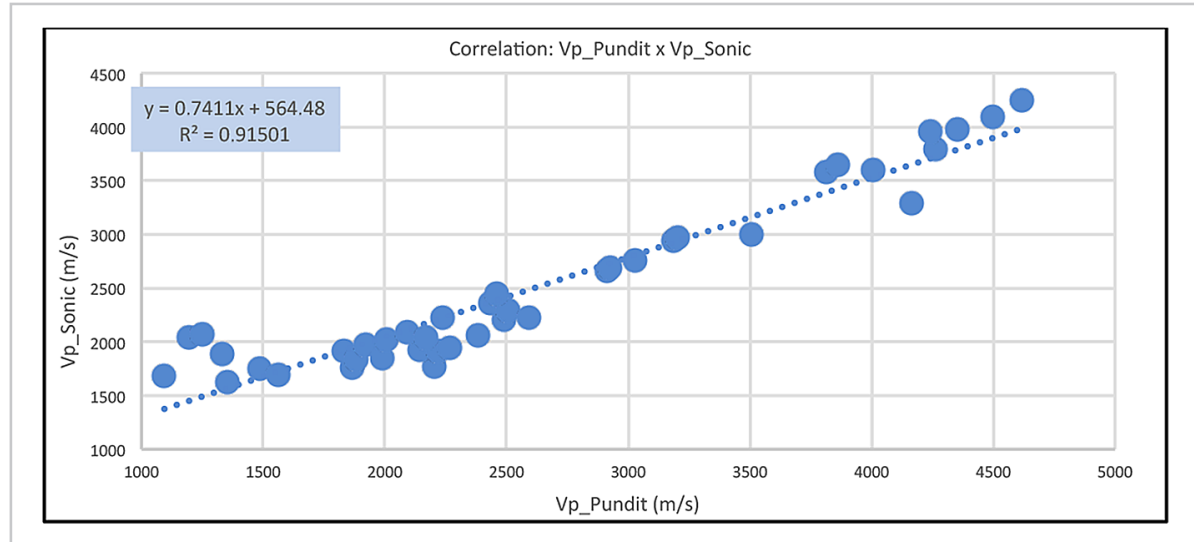

Figure 4 - Graph of the correlation between Vp_Pundit and Vp_Sonic for the set of samples used in the study.

\subsection{UCS versus $V p \_s o n i c$}

Historically, correlations between UCS and $\mathrm{Vp}$ determined by sonic logs in coal deposits use the relationship

The present study preferred to use the $U C S=A \exp (B * V p)$ ratio, where $V p=1 / t$. The above equation is not the same as that used by McNally (1987). However, it describes UCS behaviour well, described in McNally (1987) and are presented in Equation (2), where a negative exponential function is used to model

$$
\text { UCS }=143000 \mathrm{e}^{(-0.0035 \mathrm{t})}
$$

concerning $V_{p}$ obtained by sonic logging. It is also frequently used to model the correlations between UCS and the ultrasonic P-wave velocity of laboratory samples.

Figure 5 shows the correlation the correlation between UCS and Vp. In Equation (2), $\mathrm{t}$ is the $\mathrm{P}$-wave transit time (in $\mu \mathrm{s} / \mathrm{ft}$ ) and UCS is in psi.

between $V p$ obtained by sonic logging (Vp_sonic) and UCS, expressed by Equation (3), not considering lithological distinction, using the exponential relation suggested above. The determination 
coefficient obtained was $\mathrm{R}^{2}=0.73$.

UCS $=3.9273 \mathrm{e}^{\left(0.0008 \mathrm{~V}_{\mathrm{P}} \text { sonic }\right)}$

(3)

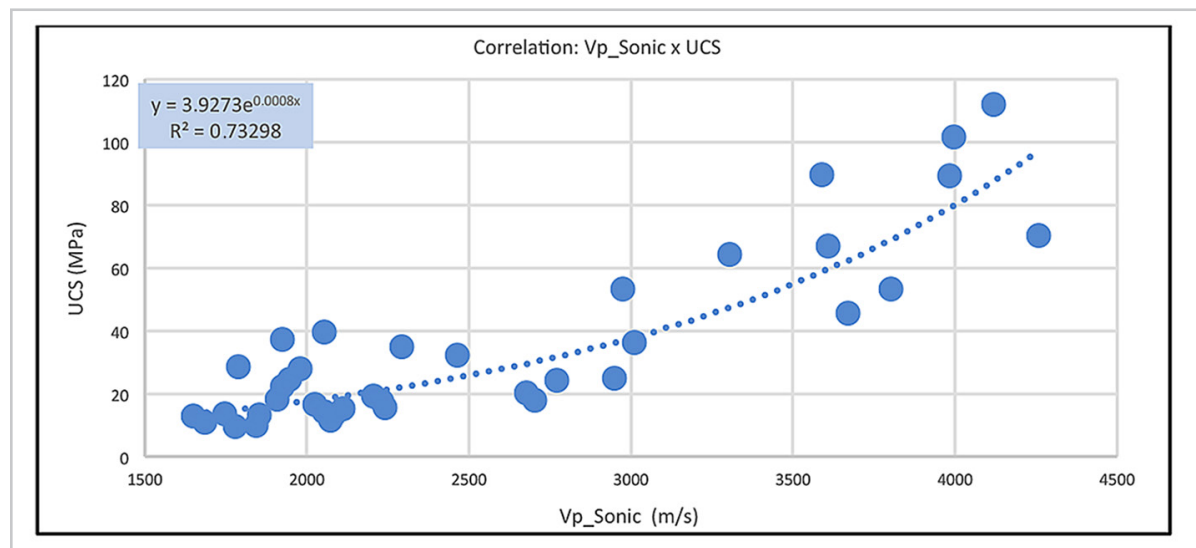

Figure 5 - Graph of general correlation between Vp_Sonic and UCS; it does not individualize the lithologies present.

Figure 6 shows the correlation $\checkmark p \_$Sonic versus UCS, but there is individualization of the lithologies present (sandstones and siltstones). For sandstones, the coefficient of determination was $R^{2}=0.88$, while the siltstone showed $\mathrm{R}^{2}=0.40$. In this case, it appears that there is different behaviour between the two lithologies, which can be captured by individualized regressions. The sandstone itself presents different behaviour con- cerning the higher values of $V_{p}$ velocities. According to the geological description of cores, $\mathrm{Vp}$ values above $3,000 \mathrm{~m} / \mathrm{s}$ were associated with cemented sandstones.

In siltstone, a lesser dispersion in UCS values (approximately 10 to 40 $\mathrm{MPa})$, while sandstone assumes a greater range of values (10 to $115 \mathrm{MPa})$. On the other hand, siltstones have lower $\mathrm{Vp}$, on average (below 3,000 m/s), while sandstones show a broader range of velocities (between 2,000 m/s and 4,300 m/s). The low siltstone velocities can be justified by the high concentration of clay in their composition, which has a lower sonic velocity.

For the results mentioned above, it is advisable that individualized correlations are used whenever the lithological types are known. Individual correlation will allow an estimate of UCS from Vp with less error.

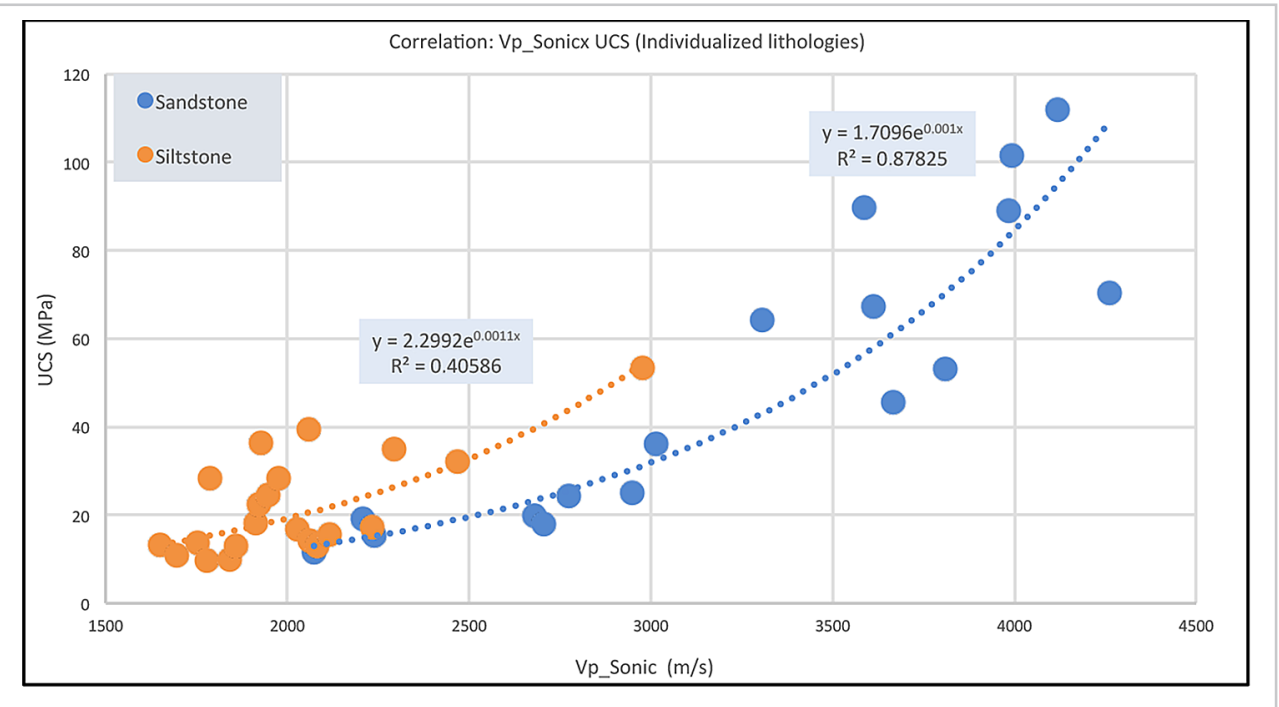

Figure 6 - Graph of correlation between Vp_Sonic and UCS, individualizing the lithologies present (sandstone and siltstone).

\subsection{UCS versus $V p \_$Pundit}

The general correlation (without individualization of lithologies) between $V$ p_Pundit and UCS (Figure 7) presents a determination index $\mathrm{R}^{2}=0.74$. This is a reasonable value that exceeds the mini- mum practical limit of 0.70 .

After calculating the general correlation index, the samples were separated by lithology. The sandstone samples showed $\mathrm{R}^{2}=0.89$, while the siltstone samples showed $\mathrm{R}^{2}=0.55$ (Figure 8). Again, the siltstone and sandstone samples behaved differently about $\mathrm{Vp}$. Equations (4) and (5) are then obtained, respectively, with sandstones showing the best correlation.

$$
\begin{aligned}
& \text { UCS }=1.4811 \mathrm{e}^{\left(0.0009 \mathrm{~V}_{-} \text {Pundit }\right)} \\
& \text { UCS }=4.9617 \mathrm{e}^{\left(0.0007 \mathrm{~V}_{\mathrm{p}} \text { Pundit }\right)}
\end{aligned}
$$




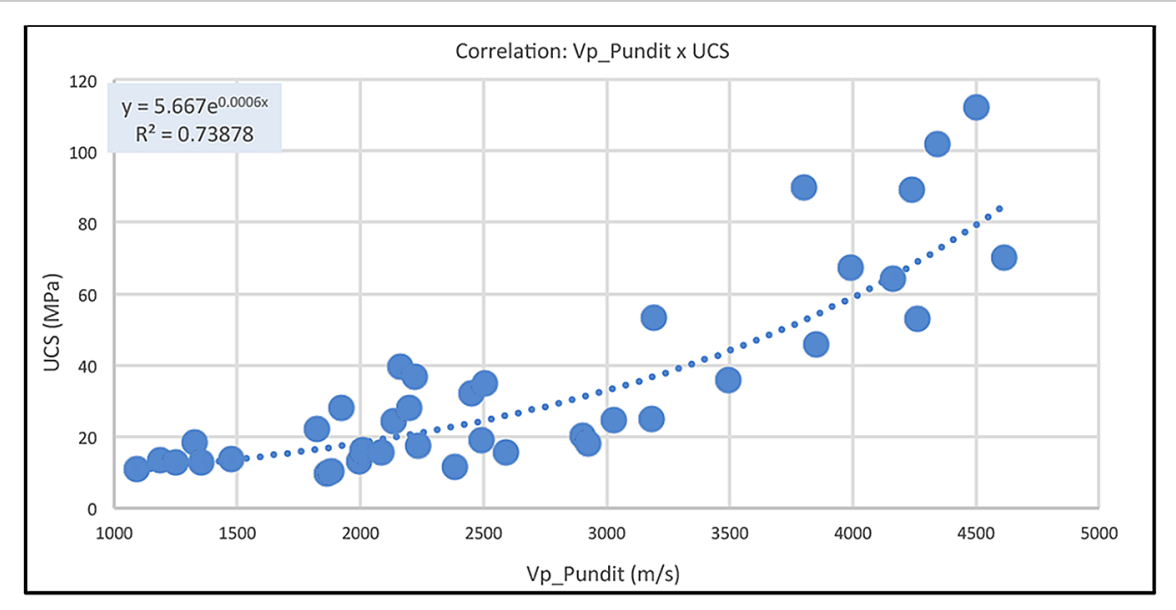

Figure 7 - General correlation graph between $V p_{-}$Pundit and UCS, not individualizing the lithologies present.

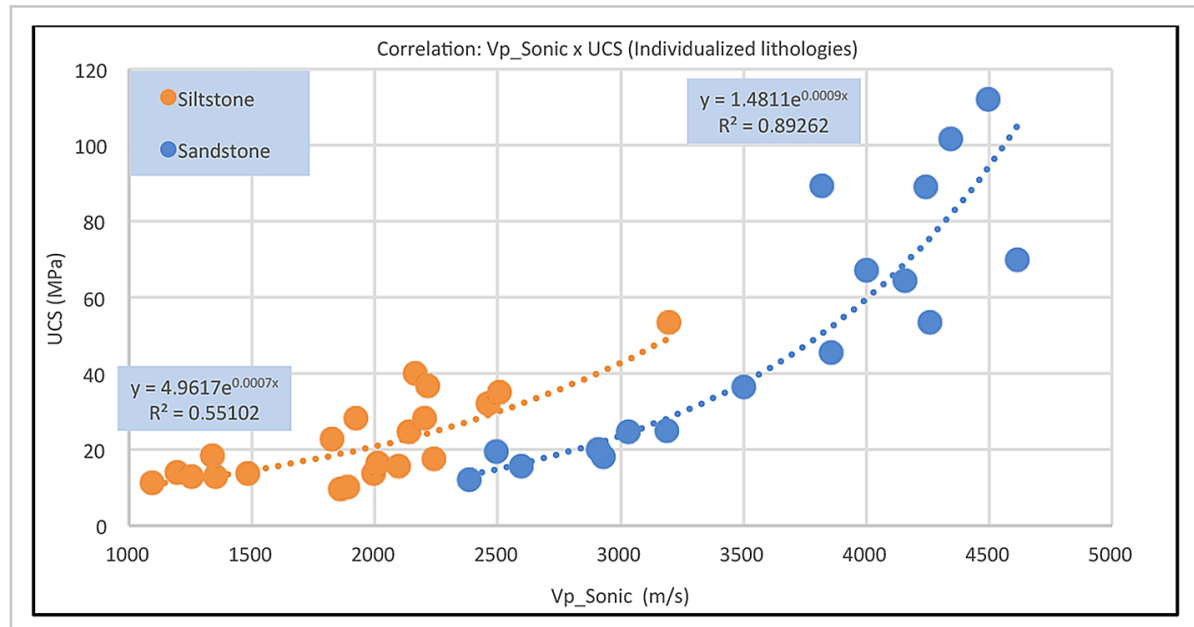

Figure 8 - Graph of correlation between $V_{p}$ Pundit and UCS, individualizing the lithologies present.

\subsection{Vp from sonic logging versus Density}

The relationship between $V p \_S o n i c$ and density, in this study, is consistent with the lithologies that address the subject. This relationship is generally increasing and linear. The density increases when the wave velocity increases, according to Figure 9, where we perceive this correspondence.

By separating the results from each lithology, it can be seen that the degree of weathering of the sandstone samples has a direct link with density and sonic wave velocity. Figure 10 illustrates this situation, dividing the samples into silt- stone, sandstone (with varying degrees of weathering) and sound sandstone.

The specific case of siltstone showed a different behaviour from sandstones, with an approximately constant density for all samples, without dependence on Vp.

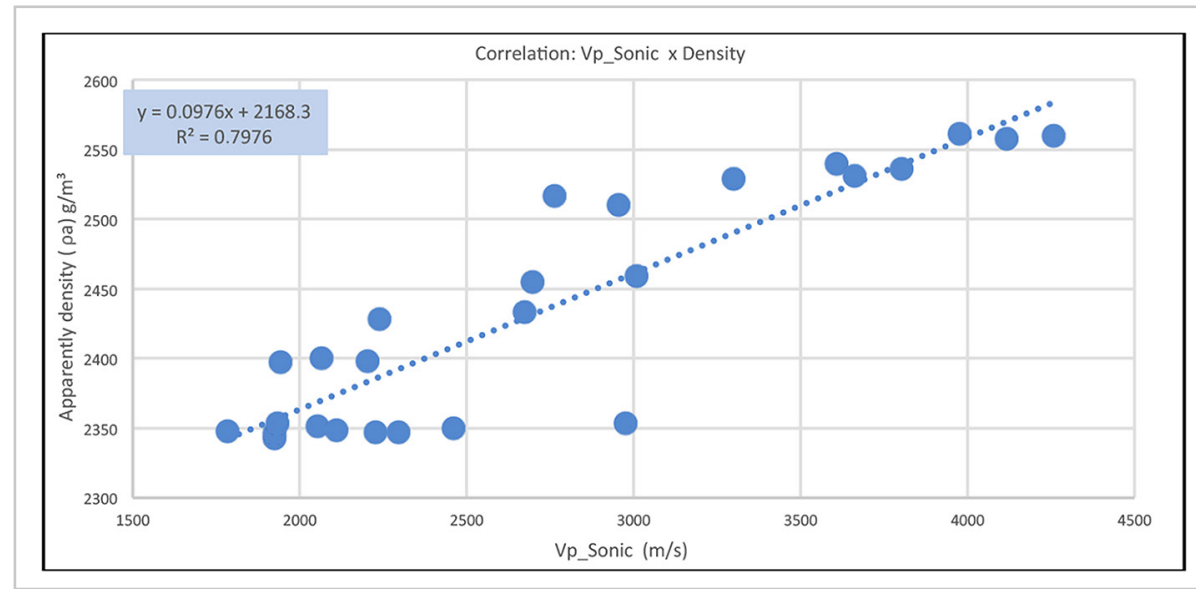

Figure 9 - Graph of correlation between $V_{p} \_$Sonic and Density; it does not individualize the lithologies present. 


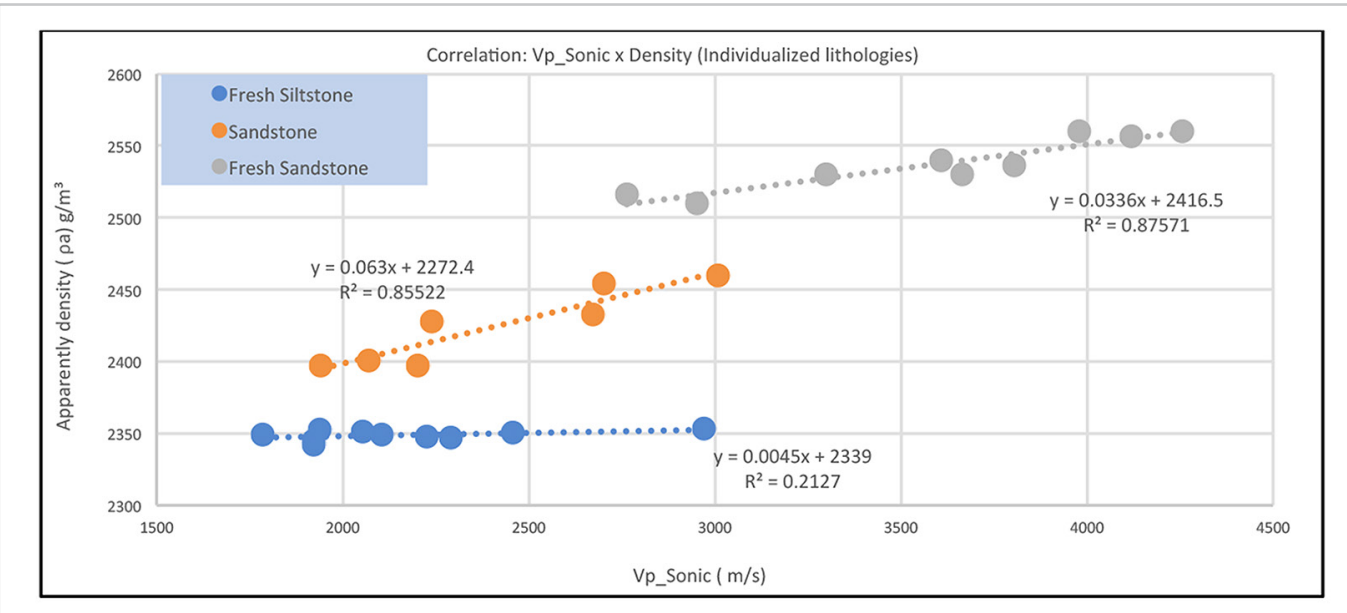

Figure 10 - Graph of correlation between Vp_Sonic and Density, individualizing the lithologies present.

\subsection{VP_Pundit versus Density}

The responses of the correlation between $V_{p}$ P Pundit and density were similar to those observed in sonic logging. This similarity between the responses provides reliability to the results. Figure 11 shows the correlation graph $V p \_$Pundit versus Density.

Figure 12 illustrates the distribution of the samples according to the lithology and the degree of weathering. Once again, this differentiation is very prominent. This duplicity of results reinforces the relationship between mineralogical constituents (lithology) and the degree of weathering with the sonic wave velocity.

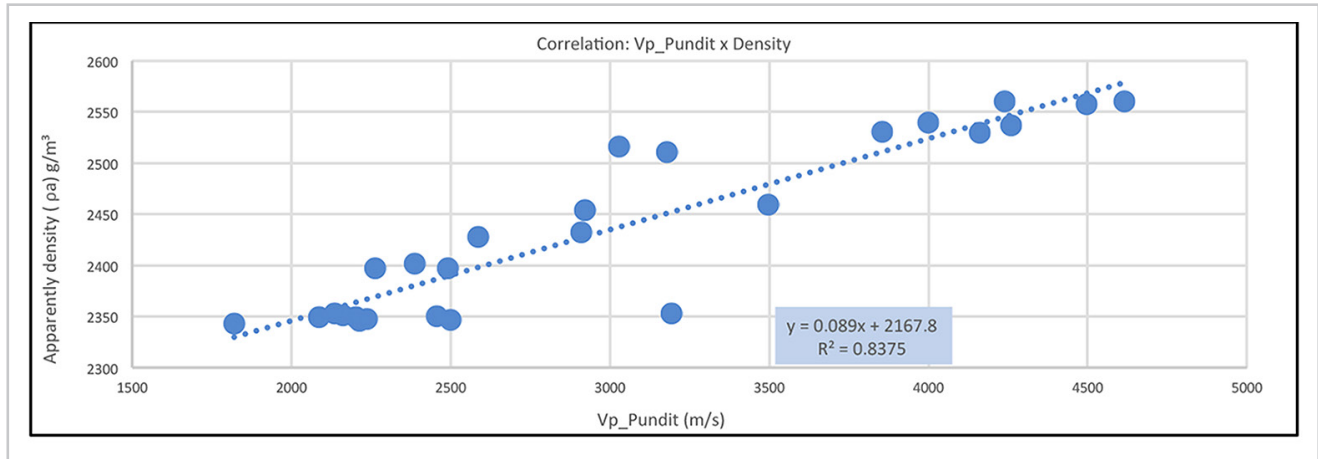

Figure 11 - General linear correlation graph between Vp_Pundit and Density, not individualizing the lithologies present.

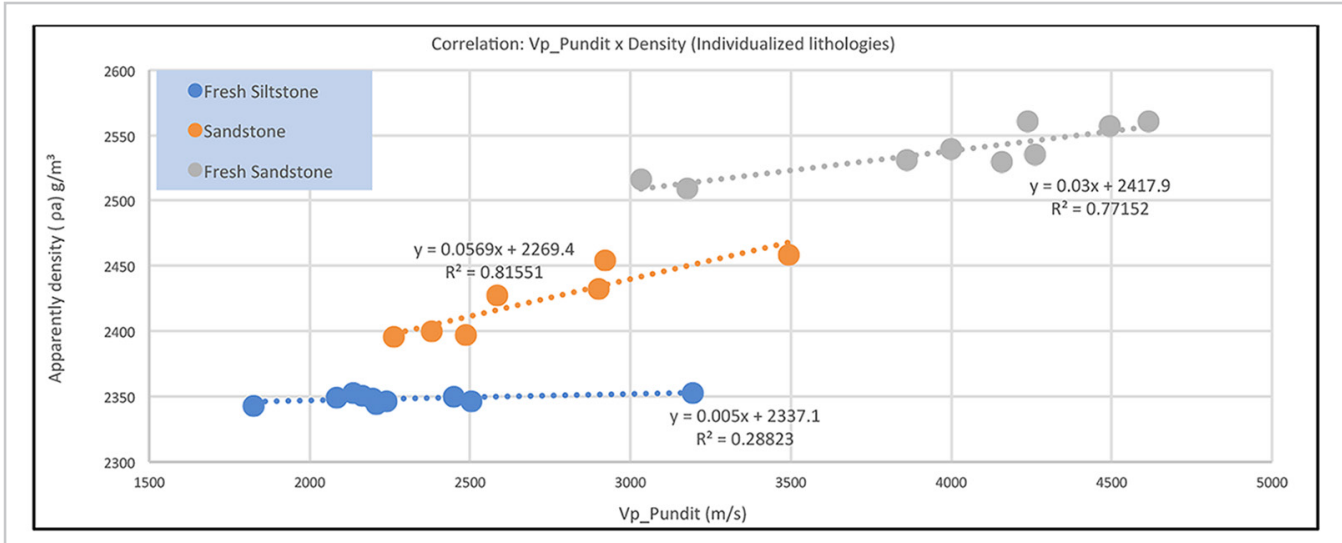

Figure 12 - Graph of correlation between Vp_Pundit and Density, individualizing the lithologies present.

\subsection{Correlation between $V p$ and Porosity}

The results obtained for the correlation between P-wave velocity and porosity show that these parameters behave in an inversely proportional way. A high degree of linear correlation (for example, above $\left.\mathrm{R}^{2}=0.70\right)$ was not obtained in both methods. Similar results were obtained (low correlations) with individualized and non-individualized lithologies.

\section{Conclusions}

This study confirmed the usefulness of indirect methods (sonic logging and ultrasonic P-wave velocity) to determine physical and mechanical parameters, such as UCS, density and porosity, in the lithologies present in a coal deposit. 
No coal samples were tested due to their unavailability. The possibility of estimating UCS (uniaxial compressive strength) from P-wave velocity is highlighted, with a high coefficient of determination $\left(\mathrm{R}^{2}\right.$ close to 0.90$)$ for sandstones, using the two indirect methods investigated.

The practical aspects of using geophysical profiling are emphasised, which dispenses sample preparation in the laboratory to determine the lithologies' $\checkmark p$ velocity. Denser, more competent, and less porous rocks had a shorter P-wave transit time and, therefore, high $V p$. The reverse occurred with less dense, less competent, and more porous massifs (possibly more weathered), presenting a smaller $V p$.

\section{References}

AMERICAN SOCIETY FOR TESTING AND MATERIALS. ASTM. D4543-01: Standard practices for preparing rock core specimens and determining dimensional and shape tolerances. West Conshohoken, PA: ASTM International, 2001.

AMERICAN SOCIETY FOR TESTING AND MATERIALS. ASTM. D2845-08: Standard test method for laboratory determination of pulse velocities and ultrasonic elastic constants of rock (withdrawn 2017). West Conshohoken, PA: ASTM International, 2008.

AMERICAN SOCIETY FOR TESTING AND MATERIALS. ASTM. D2938-95 (2002): Standard test method for unconfined compressive strength of intact rock core specimens (withdrawn 2005). West Conshohoken, PA: ASTM International,1995.

ASSOCIAÇÃO BRASILEIRA DE NORMAS TÉCNICAS. ABNT NBR 15845: Rochas para revestimento - Métodos de ensaio. Rio de Janeiro: ABNT, 2010.

ELLIS, V. D.; SINGER, M. J. Well logging for earth scientists. Dordrecht: Springer, 2007.

FENER, M. The effect of rock sample dimension on the P-wave velocity. Journal of Nondestructive Evaluation, v.30, p.99-105, 2011.

FREITAS, N. B. A., DANTAS, J. G. M., ZINGANO, A. C. Equação de correlação com ênfase na litologia para estimativa de resistência à compressão uniaxial através do uso de Pundit. In: SIMPÓSIO DE MINERAÇÃO, 18., 2017, São Paulo, Brazil. Anais [...]. São Paulo: ABM, 2017. p. 399-410.

HEARST, R. J.; NELSON, H. P.; PAILLET, L. F. Well logging for physical properties: a handbook for geophysicists, geologists and engineers. 2nd ed. Chichester, New York: Wiley, 2000.

KAHRAMAN, S. Evaluation of simple methods for assessing the uniaxial compressive strength of rock. International Journal of Rock Mechanics and Mining Sciences, v.38, p.981-94, 2001.

KAHRAMAN, S. Estimating the direct P-wave velocity value of intact rock from indirect laboratory measurements. International Journal of Rock Mechanics and Mining Science, v.39, p.101-104, 2002.

KHANDELWAL, M.; SINGH, T. N. Correlating static properties of coal measures rocks with P-wave velocity. International Journal of Coal Geology, v. 79, p. 55-60, 2009.

KHANDELWAL, M.; RANJITH, P. G. Correlating index properties of rocks with P-wave measurements. Journal of Applied Geophysics, v. 71, p. 1-5, 2010.

KARACAN, C. Ö. Elastic and shear moduli of coal measure rocks derived from basic well logs using fractal statistics and radial basis functions. International Journal of Rock Mechanics and Mining Sciences, v. 46, p. 1281-1295, 2009.

KARACAN, C. Ö. Reservoir rock properties of coal measure strata of the Lower Monongahela Group, Greene County (Southwestern Pennsylvania), from methane control and production perspectives. International Journal of Coal Geology, v. 78, p. 47-64, 2009.

KURTULUS, C.; BOZKURT, A.; ENDES, H. Physical and mechanical properties of serpentinized ultrabasic rocks in NW Turkey. Pure and Applied Geophysics, v. 169, p. 1205-1215, 2012.

MCNALLY, G. H. Estimation of coal measures rock strength using sonic and neutron logs. Geoexploration, v. 24, p. 381-395, 1987.

OYLER, D. C.; MARK, C.; MOLINDA, G. M. In situ estimation of roof rock strength using sonic logging. International Journal of Coal Geology, v. 83, p. 484-490, 2010.

PHILIPPIDIS, T. P.; AGGELIS, D. G. Experimental study of wave dispersion and attenuation in concrete. Ultrasonics, v. 43, p. 584-595, 2005.

ROBERTSON GEOLOGGING. Full-Wave Triple Sonic sonde-operating and technical manual. Deganwy, UK: Robertson Geologging, 2007.

SCHNEIDER, R.; MÜHLMANN, H.; TOMMASI, E.; MEDEIROS, R. A.; DAEMON, R. F.; NOGUEIRA, A. A. Revisão estratigráfica da Bacia do Paraná. In: CONGRESSO BRASILEIRO DE GEOLOGIA, 28., 1974, Porto Alegre. Anais [...]. [S. l.]: Sociedade Brasileira de Geologia - SBG, 1974. p. 41-65.

WADE, N. H.; HICKINBOTHAM, A. Geotechnical strength parameters from geophysical logs. International Journal of Surface Mining, Reclamation and Environment, v. 11, p. 27-32, 1997.

ZHOU, B. et al. Automated geotechnical characterisation from geophysical logs: examples from Southern Colliery, Central Queensland. Exploration Geophysics, v. 32, p. 336-339, 2001.

Received: 26 April 2021 - Accepted: 9 July 2021.

All content of the journal, except where identified, is licensed under a Creative Commons attribution-type BY. 